\title{
Intestinal Parasitic Infections Among Acute Malnourished Children During Ebola at Ratoma Medical Center of Conakry, Guinea
}

\author{
Sidibé Sidikiba $^{1,2}$, Delamou Alexandre ${ }^{1,2}$, Camara Bienvenu Salim ${ }^{1, *}$, \\ Magassouba Aboubacar Sidiki ${ }^{2}$, Ravi Nirmal ${ }^{3}$, Beavogui Abdoul Habib ${ }^{1}$ \\ ${ }^{1}$ Maferinyah National Center for Training and Research in Rural Health, Forecariah, Guinea \\ ${ }^{2}$ Faculty of Health Sciences and Techniques, Gamal Abdel Nasser University, Conakry, Guinea \\ ${ }^{3}$ eHealth Africa Guinée, Conakry, Guinea
}

Email address:

bienvenusalimcamara@gmail.com(C.B.Salim)

${ }^{*}$ Corresponding author

\section{To cite this article:}

Sidibé Sidikiba, Delamou Alexandre, Camara Bienvenu Salim, Magassouba Aboubacar Sidiki, Ravi Nirmal, Beavogui Abdoul Habib. Intestinal Parasitic Infections Among Acute Malnourished Children During Ebola at Ratoma Medical Center of Conakry, Guinea. Central African Journal of Public Health. Vol. 4, No. 2, 2018, pp. 59-64. doi: 10.11648/j.cajph.20180402.14

Received: April 15, 2018; Accepted: May 2, 2018; Published: May 5, 2018

\begin{abstract}
Intestinal parasitic infections are particularly severe in children in whom they can lead to malnutrition and decreased resistance to infections. In Guinea, no study has examined the burden of intestinal parasitic infections among malnourished children, especially in the context of the Ebola outbreak. The objective of this study was to determine the prevalence of and factors associated with intestinal parasitic infections among acute malnourished children at the Ratoma Communal Medical Center in Conakry in 2015. A 6-month cross-sectional study was conducted from April to October 2015 at the Ratoma Communal Medical Center of Conakry, Guinea. It included all children aged 6-36 months diagnosed with acute malnutrition, whose caregivers consented for the study. A total of 220 children suffering from acute malnutrition were included in the study. The prevalence of intestinal parasitic infections in the sample was $27 \%$. Different parasitic species were identified in the infected children and included Ascaris lumbricoides $(15 \%, \mathrm{n}=33)$, Enterobius vermicularis $(6 \%$, $\mathrm{n}=13)$, Entamoeba coli $(5 \%, n=11)$, and Taenia saginata $(1 \%, n=3)$. Only children's age was associated with intestinal parasitic infections $(A O R=1.37$; 95\% CI: 1.18-1.58). Household-based awareness-raising on under-five intestinal infections prevention along with deworming campaigns would constitute effective post-Ebola interventions toward the reduction of intestinal parasitic infections and malnutrition burden in under-five children in Guinea.
\end{abstract}

Keywords: Intestinal Parasitic Infections, Acute Malnutrition, Children, Ebola, Guinea

\section{Introduction}

Intestinal parasitic infections (IPIs) constitute a public health challenge especially among children in resource limited settings $[1,2]$. For instance, soil-transmitted helminthiasis affects nearly 1.5 billion people and threatens 835 million children worldwide, mostly in developing countries [1].

IPIs are linked to poor hygiene, promiscuity and extreme poverty [3-5]. They are particularly severe in children in whom they can lead among others to malnutrition and decreased resistance to infections [3-5]. Malnourished children, because of their weak immunity [6], might conversely be prone and more vulnerable to comorbidities including IPIs.

In Guinea, little is known about the prevalence of intestinal parasitic infections among children. The annual incidence rate of intestinal helminthiasis was estimated to 223 cases per 1000 population countrywide (behind malaria and upper respiratory tract infections) in 2012 [7]. However, the 2012 Demographic and Health Survey (DHS) reported that only $30 \%$ of children received dewormers during the previous six months [8]. This indicator might have worsened during the 
2014-2016 Ebola virus disease (EVD) outbreak since routine health activities slowed down [9-11] and this could include community-based activities such as deworming campaigns. In this context what's more characterized by a high prevalence of malnutrition among children (31\% for stunting and $10 \%$ for acute malnutrition) [8], intestinal parasitic infections are more likely, as comorbidity, to increase the risk of morbidity and mortality especially among acute malnourished children. It is therefore paramount to examine intestinal parasite infections among children suffering from acute malnutrition. This information could contribute guiding interventions for the reduction of both malnutrition and IPIs related morbidity and mortality among children in Guinea. To date, few studies have reported about comorbidities in Guinean malnourished children, especially in the EVD outbreak context.

The objective of this study was to determine the prevalence of and factors associated with intestinal parasitic infections among acute malnourished children at the Ratoma Communal Medical Center in Conakry in 2015.

\section{Methods}

\subsection{Study Design and Setting}

This was a 6-month cross-sectional study conducted from April to October 2015 at the Ratoma Communal Medical Center (CMC) of Conakry, Guinea.

The Ratoma CMC is the main public health facility located in the Commune of Ratoma, the largest of the five communes of Conakry (the Guinean capital city). It is a secondary level health facility covering a population of 472,629 inhabitants in 2012, of which $17 \%$ were children aged under five years [7].

\subsection{Study Population}

The study population included children aged 6-36 months diagnosed with acute malnutrition at the Pediatric Unit of the Ratoma CMC. All children in whom acute malnutrition was diagnosed, i.e. with a weight-for-height $\mathrm{z}$-score $<2$ standard deviations were included in the study [12].

\subsection{Data Collection and Study Variables}

Data were collected using a structured and standardized questionnaire, which was tested beforehand in a health center of the Ratoma commune. Data were collected from the consultation register, the patients' medical records and parasitology bulletins. They included children's sociodemographic characteristics (age, sex, caregiver's age, profession, education level, and marital status), symptoms, anthropometric values (weight, height), presence of parasites in the stool (yes/no) and treatment outcome (recovery, relapse, transfer, loss to follow up, and death). The parasitological examination of the stool samples was performed in each selected child by a laboratory technician using the direct method and the Willis technique. The stool samples were collected from the selected children on the day following the acute malnutrition diagnosis. The study data were collected by two trained medical students. A verbal consent was obtained from each child's caregiver before collecting data.

\subsection{Data Analysis}

Descriptive variable were presented as proportions or median (with $25 \%$ and $75 \%$ interquartile range). To identify the factors associated with the presence of parasite in the stool, the Pearson Chi Square, Fischer and Student t tests were used to compare the prevalence of intestinal parasitic infections across the study variables in bivariate analysis. All variables with a $P$ value $\leq 0.20$ were included in the logistic regression model. The unadjusted and adjusted odds ratios were derived. The significance level was set at $5 \%$ with a 95\% confidence interval.

The data were analyzed using the EPI Info software version 7.1.5 (Epi Info TM, CDC Atlanta, USA).

\subsection{Ethical Considerations}

The protocol of the study was approved by the Scientific Committee of the Chair of Public Health, Faculty of Medicine, and University of Conakry. An inform consent was obtained from each child's caregiver prior to data collection.

\section{Results}

Socio-demographic and clinical characteristics of children A total of 220 children suffering from acute malnutrition were included in the study. They were predominantly females $(55.45 \%)$ and had a median age of 10 months with $25 \%$ and $75 \%$ interquartile range (IQR) of 8 and 14 months (Table 1). They had a median weight of $6.9 \mathrm{~kg}$ (IQR: 6.3-7.5 kg), a median height of $70 \mathrm{~cm}$ (IQR: $66.5-74 \mathrm{~cm}$ ), and mostly recovered $(84.55 \%)$ after the treatment received at the medical center. Children's caregivers had a median age of 25.5 years (IQR: 21.5-30 years); they were married/in union $(83.64 \%)$, and housewives $(34.55 \%)$, with secondary school or more level $(55 \%)$.

Table 1. Socio-demographic characteristics and treatment outcome of acute malnourished children aged 6 to 36 months, seen in Ratoma Communal Medical Center, Conakry (Guinea) (N=220), April-October 2015.

\begin{tabular}{lll}
\hline Variables & Number & $\%$ \\
\hline Median age (IQR), months & $10(8-14)$ & \\
Sex & & \\
Male & 98 & 44.55 \\
Female & 122 & 55.45 \\
Median height (IQR), cm & $70(66.5-74)$ & \\
Median weight (IQR), kg & $6.9(6.3-7.5)$ & \\
Caregiver's median age (IQR), years & $25.5(21.5-30)$ & \\
Caregiver's profession & & \\
Housewife & 76 & 34.55 \\
Seller & 48 & 21.82 \\
Employee & 33 & 15 \\
Student & 32 & 14.55 \\
Workwoman & 29 & 13.18 \\
Singer & 2 & 0.91 \\
Caregiver's education level & & \\
None & 52 & 23.64 \\
\hline
\end{tabular}




\begin{tabular}{lll}
\hline Variables & Number & \% \\
\hline Primary & 47 & 21.36 \\
Secondary or more & 121 & 55 \\
Caregiver's marital status & & \\
Unmarried & 36 & 16.36 \\
Married/In union & 184 & 83.64 \\
Treatment outcome & & \\
Recovery & 186 & 84.55 \\
Loss to follow up & 30 & 13.64 \\
Death & 4 & 1.82 \\
\hline
\end{tabular}

Children's symptoms are shown in Figure 1. Most of them presented with emaciation ( $80 \%)$, followed by candida $(40 \%)$ and diarrhea $(40 \%)$, anorexia (35\%), greenish stools $(26 \%)$, vomiting $(17 \%)$, and glairy stools $(15 \%)$. Few children $(\leq$ $2 \%$ ) had palor, anal pruritus, abdominal pain, conjunctivitis, abdominal bloating, dehydration, or meteorism.

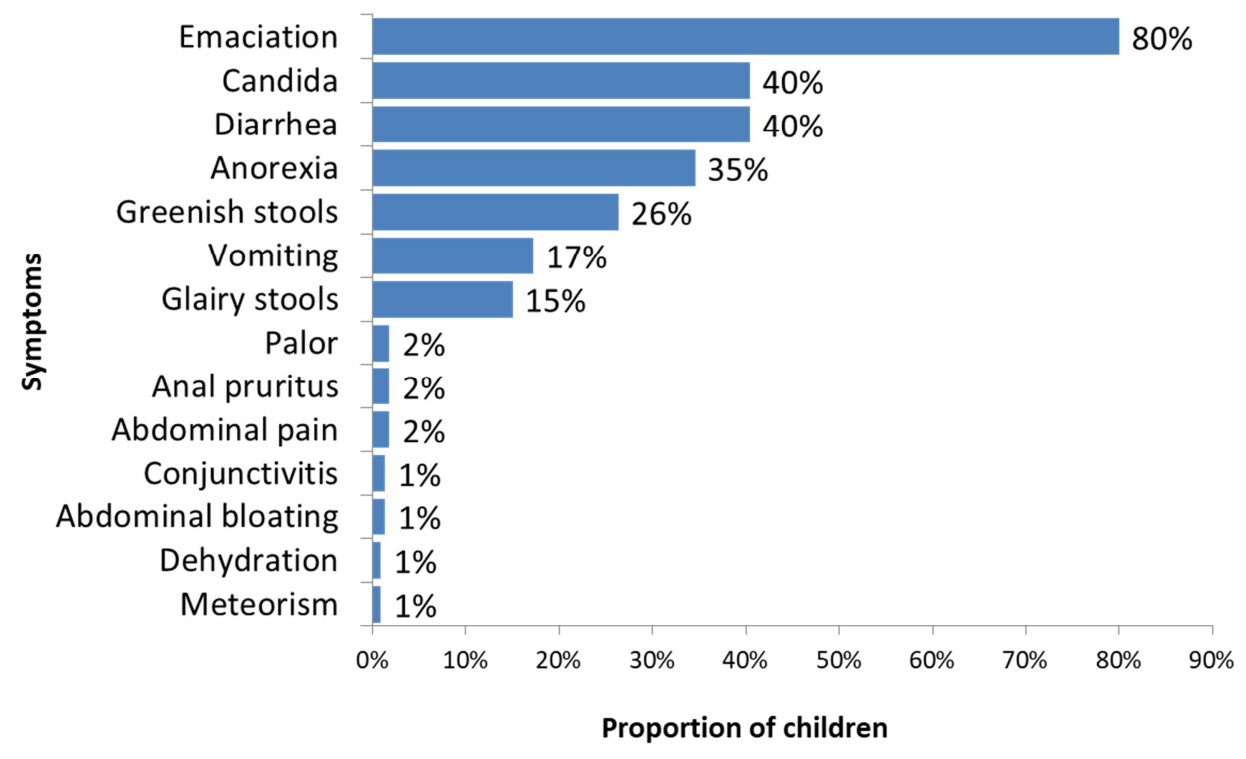

Figure 1. Symptoms in acute malnourished children aged 6 to 36 months, seen in Ratoma Communal Medical Center, Conakry (Guinea) (N=220), AprilOctober 2015.

Prevalence of and factors associated with intestinal parasitic infections

The prevalence of intestinal parasitic infections among the sampled children was $27 \%(\mathrm{n}=60)$ (Figure 2). Different parasitic species were identified in the infected children and included Ascaris lumbricoides $(15 \%, \mathrm{n}=33)$, Enterobius vermicularis $(6 \%$, $\mathrm{n}=13)$, Entamoeba coli $(5 \%, \mathrm{n}=11)$, and Taenia saginata $(1 \%, \mathrm{n}=3)$.

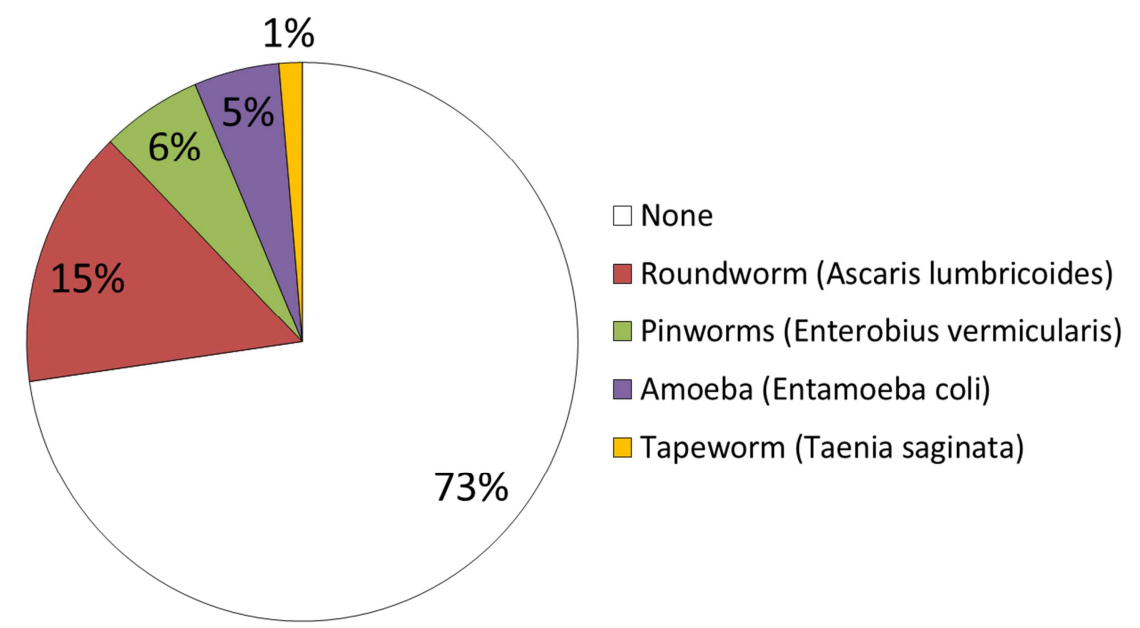

Figure 2. Prevalence of intestinal parasitic infections among acute malnourished children aged 6 to 36 months, seen in Ratoma Communal Medical Center, Conakry (Guinea) (N=220), April-October 2015.

The bivariate analysis showed that children's age, height, weight, and the presence of candida were associated with intestinal parasitic infections. However in the multivariate analysis, only children's age was associated with intestinal parasitic infections. They had a mean age positively associated with intestinal parasitic infections, with an AOR=1.37 (95\% CI: 1.181.58). 
Table 2. Factors associated with intestinal parasitic infections among acute malnourished children aged 6 to 36 months, seen in Ratoma Communal Medical Center, Conakry (Guinea) (N=220), April-October 2015.

\begin{tabular}{|c|c|c|c|c|}
\hline \multirow{2}{*}{ Characteristics } & \multicolumn{4}{|c|}{ Presence of intestinal parasitic infection (yes) } \\
\hline & $\mathbf{N}(\%)$ & Unadjusted OR (95\% CI) & Adjusted OR (95\% CI) & $P$-value \\
\hline Mean age (SD) & $16.31(6.32)$ & $1.35(1.23-1.48)$ & $1.37(1.18-1.58)$ & $<.001$ \\
\hline \multicolumn{5}{|l|}{ Sex } \\
\hline Male & $27(27.55)$ & 1 & & \\
\hline Female & $33(27.05)$ & $0.97(0.54-1.77)$ & - & .93 \\
\hline Mean height (SD) & $74.87(5.87)$ & $1.21(1.13-1.29)$ & $0.9(0.75-1.08)$ & .25 \\
\hline Mean weight (SD) & $7.61(1.04)$ & $2.58(1.81-3.68)$ & $1.69(0.75-3.8)$ & .21 \\
\hline Caregivers' mean age (SD) & $25.65(5.64)$ & $0.98(0.93-1.04)$ & - & .47 \\
\hline \multicolumn{5}{|l|}{ Caregiver's profession } \\
\hline Housewife & $18(23.68)$ & 1 & & \\
\hline Other profession ${ }^{\mathrm{a}}$ & $42(29.17)$ & $1.33(0.7-2.51)$ & - & .39 \\
\hline \multicolumn{5}{|l|}{ Caregiver's education level } \\
\hline None & $13(25)$ & 1 & & \\
\hline Primary & $15(31.91)$ & $1.41(0.58-3.38)$ & - & .45 \\
\hline Secondary or more & $32(26.45)$ & $1.08(0.51-2.28)$ & - & .84 \\
\hline \multicolumn{5}{|l|}{ Caregiver's marital status } \\
\hline Married/In union & $53(28.8)$ & 1 & & \\
\hline Unmarried & 7 (19.44) & $0.6(0.25-1.45)$ & - & .25 \\
\hline \multicolumn{5}{|l|}{ Presence of emaciation } \\
\hline Yes & $30(33.71)$ & $1.71(0.94-3.12)$ & - & .08 \\
\hline No & $30(22.9)$ & 1 & & \\
\hline \multicolumn{5}{|l|}{ Presence of candida } \\
\hline Yes & $14(15.73)$ & $0.34(0.18-0.68)$ & $0.52(0.24-1.15)$ & .11 \\
\hline No & $46(35.11)$ & 1 & 1 & \\
\hline \multicolumn{5}{|l|}{ Presence of diarrhea } \\
\hline Yes & $30(33.71)$ & $1.71(0.94-3.12)$ & - & .08 \\
\hline No & $30(22.9)$ & 1 & & \\
\hline \multicolumn{5}{|l|}{ Presence of anorexia } \\
\hline Yes & $21(27.63)$ & $1.03(0.55-1.92)$ & - & .93 \\
\hline No & $39(27.08)$ & 1 & & \\
\hline \multicolumn{5}{|l|}{ Presence of greenish stools } \\
\hline Yes & $18(31.03)$ & $1.29(0.67-2.48)$ & - & .45 \\
\hline No & $42(25.93)$ & 1 & & \\
\hline \multicolumn{5}{|l|}{ Presence of vomiting } \\
\hline Yes & $10(26.32)$ & $0.94(0.43-2.08)$ & - & .88 \\
\hline No & $50(27.47)$ & 1 & & \\
\hline \multicolumn{5}{|l|}{ Presence of glairy stools } \\
\hline Yes & $13(39.39)$ & $1.94(0.89-4.19)$ & - & .09 \\
\hline No & $47(25.13)$ & 1 & & \\
\hline \multicolumn{5}{|l|}{ Treatment outcome } \\
\hline Recovery & $53(28.49)$ & 1 & & \\
\hline Loss to follow up & $5(16.67)$ & $0.50(0.18-1.38)$ & - & .18 \\
\hline Death & $2(50)$ & $2.5(0.34-1.38)$ & - & .36 \\
\hline
\end{tabular}

${ }^{a}$ Seller, employee, student, workwoman, singer

\section{Discussion}

This study is the first to examine intestinal parasitic infections (IPIs) among malnourished children in the Ebola virus Disease (EVD) context in Guinea. It showed that more than one acute malnourished child out of four $(27 \%)$ seen at Ratoma Communal Medical Center in Conakry had IPIs, with Ascaris lumbricoides being responsible for more than half of these infections. The IPIs were associated with children's age. With regard to the progress to be achieved in child health as a result of the regular deworming campaigns ongoing in the country since years [13], the prevalence of IPIs found among acute malnourished children in our study is likely to indicate a drawback in controlling IPIs among Guinean children. An unpublished study (Kamano et al,
Medical thesis, University of Conakry, 2008) reported lower prevalence of IPIs (20\%) among acute malnourished children aged 6 to 59 months in the National Institute of Child Health (INSE) in Conakry in 2008 [14]. With the passing of the EVD outbreak that decreased utilization of health services in the country, child health indicators worsened over the years 2015-2016 [9, 10]. The present finding therefore advocates for appropriate actions such as sustaining health coverage for under-five children for essential services like deworming campaigns, regardless of the epidemic context. In addition, another implication of the high prevalence of IPIs among acute malnourished children is the need for systematic investigation (stool examination) on IPIs in any child diagnosed with malnutrition.

This study suggests that more children were old, more they were likely to have IPIs. This should be explained by two 
main facts. First, children, as they grow, are more likely to stay far from their caregivers, exposing them to the risk of handling infected/dusty stuffs. Since from the age of four months, the cognitive development of children makes them use their mouth to learn by feeling things out [15], the risk of ingesting infectious germs such as worm eggs/larva should therefore be higher as they grow up [16]. Most IPIs are transmitted by eggs present in human feces, which contaminate the soil in areas where sanitation is poor [1]. Second, children progressively lose their maternal immunity as they grow, thus making them more vulnerable to infections [17]. Bechir et al [18] in Chad in 2008 found that children aged 25 to 59 months had higher prevalence of IPIs than those of lower age group. Household-based awarenessraising on under-five intestinal infections prevention, e.g caregivers' sensitization on IPIs prevention along with the deworming campaigns would contribute to decrease IPIs burden among elder under-five children. A national survey in 2016 showed that in Guinea, only $26.5 \%$ of households had improved drinking water sources and toilets and that more than one-third of children aged 0 to 2 years in these households had feces safely evacuated [19].

More than half of the infected children in this sample had Ascaris lombricoides. Despite being reported as one of the commonest helminthes among children in sub-Sahara Africa $[18,20]$, this parasite species is known to impair nutritional status [1] and has been found among other helminthes to be associated with malnutrition in children [21]. This emphasizes the importance of deworming interventions, especially controlling helminthiasis, as key part of malnutrition prevention among children.

The present study had some limitations. The study population was limited to acute malnourished children. Inclusion of children without malnutrition could help to better understand the IPIs burden related to acute malnourished children. The study was also circumscribed to children presenting at a health facility. It therefore cannot give actual prevalence of IPIs among malnourished children since those not attending the selected facility were not included. However, this study has the merit to inform on infacility IPIs burden among malnourished children in the particular context of the EVD. It also has important implications for post-EVD public health practices and policy for child health improvement in Guinea.

\section{Conclusion}

The findings of this study showed that more than one acute malnourished child out of four (27\%) seen at Ratoma Communal Medical Center in Conakry during the EVD outbreak had IPIs, with Ascaris lumbricoides being responsible for more than half of these infections. The IPIs were associated with children's age.

This study urges for sustainable and regular deworming campaigns irrespective of the epidemic context. What's more, household-based awareness-raising of caregivers on child infections prevention with an emphasis on intestinal parasitic infections would contribute to decrease IPIs burden among Guinean children.

In addition, for better child health outcomes, this study recommends to Guinean medical practitioners to systematically investigate on IPIs in front of any case of under-five acute malnutrition.

\section{Authors' Contributions}

$\mathrm{SS}$ and $\mathrm{AD}$ were involved with conception and design of the protocol. SS, BSC, ASM were involved with acquisition of data. SS, BSC, AD and ASM did the data analysis and all authors were involved with interpretation. All authors have given approval for the final version to be published and are accountable. All authors read and approved the final version.

\section{Conflict of Interest}

The authors declare that they have no competing interests.

\section{References}

[1] WHO. Soil-transmitted helminth infections. [Internet]. Fact sheet. 2017 [cited 2017 Jan 1]. Available from: http://www.who.int/mediacentre/factsheets/fs366/en/.

[2] CDC. Parasites: children. [Internet]. 2015 [cited 2017 Dec 2]. Available from: https://www.cdc.gov/parasites/children.html.

[3] Vercruysse J, Behnke JM, Albonico M, Ame SM, Angebault C, Bethony JM, et al. Assessment of the anthelmintic efficacy of albendazole in school children in seven countries where soil-transmitted helminths are endemic. PLoS Negl Trop Dis. 2011; 5 (3).

[4] El Kettani S, Azzouzi EM, Maata A. Prévalence de Giardia intestinalis chez une population rurale utilisant les eaux usées à des fins agricoles à Settat, Maroc. Med Mal Infect. 2006; 36 (6):322-8.

[5] Raccurt C, Pannier-Stockman C, Eyma E, Verdier R, Totet A, Pape J. Parasites intestinaux et SIDA en Haiti: faut-il deparasiter l'entourage familial? Med Trop. 2006; (66):461-4.

[6] Bourke CD, Berkley JA, Prendergast AJ. Immune Dysfunction as a Cause and Consequence of Malnutrition. Trends Immunol. 2016; 37 (6):386-98.

[7] MSHP Guinee. Annuaire des statistiques sanitaires nationales 2012. Conakry; 2015.

[8] Institute of Statistics. Guinea Demographic and Health and Multiple Indicators Survey 2012. 2013.

[9] Camara BS, Delamou A, Diro E, El Ayadi AM, Beavogui AH, Sidibé S, et al. Influence of the 2014-2015 Ebola outbreak on the vaccination of children in a rural district of Guinea. Public Heal Action. 2017; 7 (2):161-7.

[10] Delamou A, Delvaux T, El Ayadi AM, Beavogui AH, Okumura J, Van Damme W, et al. Public health impact of the 2014-2015 Ebola outbreak in West Africa: seizing opportunities for the future. BMJ Glob Heal. 2017; 2 (2): $\mathrm{e} 000202$. 
[11] Fribault M. Ebola en Guinée : violences historiques et régimes de doute. Anthropologie \& Santé. 2015.

[12] WHO. Global Database on Child Growth and Malnutrition [Internet]. 2017 [cited 2017 Dec 1]. Available from: http://www.who.int/nutgrowthdb/about/introduction/en/index5 .html.

[13] OMS Guinee. Sante de l'enfant: le Premier Ministre lance la campagne integree [Internet]. Bulletin bimestriel de la Representation de l'OMS en Guinee, Numero 11. 2009 [cited 2017 Dec 17].p. 1-6. Available from:

http://www.who.int/hac/crises/gin/sitreps/guinee_oms_sante_n ovembre2009. pdf.

[14] Kamano C. Malnutrition Aigüe et parasitose intestinales chez les enfants de 6 à 59 mois: Aspects épidémiologiques, cliniques et thérapeutique l'INSE. Gamal Abdel Nasser University of Conakry; 2008.

[15] Oswalt A. Infancy Cognitive Development [Internet]. Gracepoint. 2017 [cited 2017 Dec 16]. Available from: https://www.gracepointwellness.org/461-child-developmentparenting-infants-0-2/article/10113-infancy-cognitivedevelopment-continued.

[16] Eisai Co. Neglected tropical diseases and three major infectious diseases [Internet]. 2014 [cited 2017 Dec 16].
Available from:

http://atm.eisai.co.jp/english/ntd/helminthiasis.html.

[17] Simon AK, Hollander GA, McMichael A. Evolution of the immune system in humans from infancy to old age. Proc R Soc B Biol Sci. 2015; 282 (1821):20143085.

[18] Bechir M, Schelling E, Hamit MA, Tanner M, Zinsstag J. Parasitic infections, anemia and malnutrition among rural settled and mobile pastoralist mothers and their children in chad. Ecohealth. 2012; 9 (2):122-31.

[19] Institut National de la Statistique. Rapport des résultats clés: Suivi de la situation des enfants et des femmes. MICS 2016. 2017.

[20] Adeniran AA, Mogaji HO, Aladesida AA, Olayiwola IO, Oluwole AS, Abe EM, et al. Schistosomiasis, intestinal helminthiasis and nutritional status among preschool-aged children in sub-urban communities of Abeokuta, Southwest, Nigeria. BMC Res Notes. 2017; 10 (1):637.

[21] Opara K, Udoidung N, Opara D. The impact of intestinal parasitic infections on the nutritional status of rural and urban school-aged children in Nigeria. Int 2012; 1 (1):73-82. 